\title{
LACTATE-PROTON CO-TRANSPORT AND ITS CONTRIBUTION TO INTERSTITIAL ACIDIFICATION DURING HYPOXIA IN ISOLATED RAT SPINAL ROOTS
}

\author{
U. Schneider, ${ }^{*} \dagger$ R. C. Poole,$\ddagger$ A. P. Halestrap $\ddagger$ and P. Grafe $\dagger$ \\ †Department of Physiology, University of Munich, Pettenkoferstr. 12, W-8000 München 2, Germany \\ $\ddagger$ Department of Biochemistry, School of Medical Sciences, University of Bristol, Bristol BS8 ITD, U.K.
}

\begin{abstract}
Exposure of nervous tissue to hypoxia results in interstitial acidification. There is evidence for concomitant decrease in extracellular $\mathrm{pH}$ to the increase in tissue lactate. In the present study, we used double-barrelled $\mathrm{pH}$-sensitive microelectrodes to investigate the link between lactate transport and acid-base homeostasis in isolated rat spinal roots. Addition of different organic anions to the bathing solution at constant bath $\mathrm{pH}$ caused transient alkaline shifts in extracellular $\mathrm{pH}$; withdrawal of these compounds resulted in transient acid shifts in extracellular $\mathrm{pH}$. With high anion concentrations $(30 \mathrm{mM})$, the largest changes in extracellular $\mathrm{pH}$ were observed with propionate $>\mathrm{L}$-lactate $\approx$ pyruvate $>2$-hydroxy-2-methylpropionate. Changes in extracellular $\mathrm{pH}$ induced by $10 \mathrm{mM}$ L- and D-lactate were of similar size. Lactate transport inhibitors $\alpha$-cyano-4-hydroxycinnamic acid and 4,4'-dibenzamidostilbene-2,2'-disulphonic acid significantly reduced L-lactate-induced extracellular $\mathrm{pH}$ shifts without affecting propionate-induced changes in extracellular pH. Hypoxia produced an extracellular acidification that was strongly reduced in the presence of $\alpha$-cyano-4-hydroxycinnamic acid and 4,4'-dibenzamidostilbene-2,2'-disulphonic acid. In contrast, amiloride and $4,4^{\prime}$-di-isothiocyanostilbene-2,2'-disulphonate were without effect on hypoxia-induced acid shifts.

The results indicate the presence of a lactate-proton co-transporter in rat peripheral nerves. This transport system and not $\mathrm{Na}^{+} / \mathrm{H}^{+}$or $\mathrm{Cl}^{-} / \mathrm{HCO}_{3}^{-}$exchange seems to be the dominant mechanism responsible for interstitial acidification during nerve hypoxia.
\end{abstract}

Interstitial acidosis in the nervous system has long been recognized to be a consequence of repetitive electrical stimulation, seizure activity, superfusion with high $\mathrm{K}^{+}$concentrations and/or exposure to hypoxia. ${ }^{7}$ Experimental evidence suggests that lactic acid production may underlie extracellular acid shifts in some of these conditions: (a) a close correlation in the time courses of change in extracellular $\mathrm{pH}$ and lactate was found during and after cortical spreading depression; ${ }^{29,37}$ (b) inhibition of glycolysis antagonized the interstitial acidification during superfusion of rat cerebellum with $40 \mathrm{mM} \mathrm{K} \mathrm{K}^{+.24}$ (c) a clear correlation between glucose availability of neural tissue and the extent of hypoxia-induced acidification was shown both in vivo ${ }^{8,40}$ and in vitro. ${ }^{25,42}$ However, the mechanism involved in transmembrane proton extrusion during lactacidosis in the nervous system is not clear. ${ }^{7}$ On the one hand, transport of lactate has been described in the striatum, ${ }^{26}$ in hippocampal slices, ${ }^{2}$ and in cultured astrocytes and neurons. ${ }^{45}$ On the other hand, the contribution of a lactate-proton co-transporter to extracellular acid shifts in the

*To whom correspondence should be addressed.

Abbreviations: CHC, a-cyano-4-hydroxycinnamic acid; DBDS, 4,4'-dibenzamidostilbene-2,2'-disulphonic acid; DIDS, 4,4'-di-isothiocyanostilbene-2,2'-disulphonate; HEPES, $\quad N$-2-hydroxyethylpiperazine- $N^{\prime}$-2-ethanesulphonic acid; HPL, DL-p-hydroxyphenyl-lactic acid $\mathrm{pH}_{\mathrm{e}}$, extracellular (interstitial) $\mathrm{pH}$. nervous system has not yet been demonstrated. On the contrary, Krnjevic and $W_{a l z}{ }^{25}$ reported that DL-p-hydroxyphenyl-lactic acid (HPL), a weak inhibitor of lactate transport in Ehrlich ascites tumour cells $\left(K_{i} 3.6 \mathrm{mM}\right){ }^{41}$ failed to diminish acid transients evoked by anoxia in rat hippocampal slices, and concluded that these are not mediated principally by lactate transport.

Co-transport of lactate and protons, mediated by a specific transporter, has been clearly demonstrated in Ehrlich ascites tumour cells, ${ }^{41}$ erythrocytes, ${ }^{10,12}$ canine $^{43}$ and guinea-pig ${ }^{30}$ cardiac myocytes, skeletal muscle from rat $^{23,36}$ and frog, ${ }^{28}$ rat liver cells ${ }^{13}$ and rabbit corneal epithelium. ${ }^{5}$ On the other hand, passive diffusion of lactic acid as a dominant pathway for lactate transport has been shown in toadfish hepatocytes ${ }^{44}$ and L6 myoblasts. ${ }^{4}$ Indeed, in all cells some diffusion of lactic acid can occur, resulting in similar proton fluxes, but these are not sensitive to inhibitors of the transporter. ${ }^{10}$

In the present study, we have used double-barrelled $\mathrm{pH}$-sensitive microelectrodes to investigate the link between lactate transport and acid-base homeostasis in isolated rat spinal roots. The effects of lactate and other organic anions on the extracellular $\mathrm{pH}$ $\left(\mathrm{pH}_{\mathrm{e}}\right)$ of spinal roots were studied under normoxic and hypoxic conditions, in the presence and absence of inhibitors of lactate-proton co-transporters. This enabled us to determine the dominant 
transmembrane pathway for lactate and the mechanisms underlying the hypoxia-induced acidification in rat peripheral nerves.

Some preliminary results of this study have been presented in abstract form at a meeting of the German Physiological Society. ${ }^{39}$

\section{EXPERIMENTAL PROCEDURES}

Animals and preparation

Male Wistar rats, weighing $300-400 \mathrm{~g}$, were obtained from Thomae, Biberach, Germany. The animals were anaesthetized with urethane $(1.5 \mathrm{~g} / \mathrm{kg}$, i.p., supplemented as required) for a laminectomy to expose the cauda equina and the spinal ganglia. Spinal roots were removed in their entire length (from the spinal cord to the spinal nerve) for in vitro recordings. The anatomical relationship of the isolated roots to the spinal ganglia enabled us to differentiate between dorsal and ventral roots. After preparation the spinal roots were stored in the standard solution containing $2.5 \mathrm{mM}$ glucose at room temperature until they were transferred to the experimental organ bath

\section{Experimental set-up}

Recordings from isolated rat spinal roots were made in a commercially available three-chambered plexiglas organ bath (Marsh ganglion bath; Hugo Sachs Elektronik, March-Hugstetten, Germany), which has been described previously. ${ }^{38}$ A constant superfusion of the spinal root in the central compartment with temperature-adjusted saline $\left(36^{\circ} \mathrm{C}\right.$, flow rate $13 \mathrm{ml} / \mathrm{min}$ ) was produced by means of gas pressure in a closed perfusion system. ${ }^{42}$ The $p \mathrm{O}_{2}$ was monitored continuously by a Clark style electrode (Diamond Electro-Tech Inc., Ann Arbor, MI, U.S.A.) and was found to be less than $3 \mathrm{mmHg}$ in the hypoxic solution. The end of a spinal root in one of the lateral compartments was drawn into a suction electrode which was used for stimulation of A fibres (supramaximal single square voltage pulses; duration: $0.1 \mathrm{~ms}$, stimulation rate: $0.2 \mathrm{~Hz}$ ). A pair of silver chloride/agar electrodes in the central and the other lateral compartment of the organ bath was used to record compound nerve action potentials and the extracellular $d . c$. potential. The amplitude of the A fibre compound action potential (peak height) was measured continuously by means of a peak detector.

\section{pH-sensitive microelectrodes}

Double-barrelled $\mathrm{pH}$-sensitive microelectrodes of the twisted type were constructed according to a method described in detail by Ballanyi and Schlue. ${ }^{3}$ The central barrel contained the pH-sensitive cocktail (Hydrogen Ion Ionophore I-Cocktail A 95291; Fluka, Buchs, Switzerland) and was backfilled with a mixed electrolyte solution of $100 \mathrm{mM}$ sodium citrate and $100 \mathrm{mM}$ sodium chloride $\mathrm{(pH}$ adjusted to 6.0 ). The reference barrel was filled with $1 \mathrm{M}$ magnesium acetate solution. Each electrode was calibrated in a HEPES $(6 \mathrm{mM})$-buffered standard solution adjusted to pH 7.4 and in a piperazine- $N, N^{\prime}$-bis-ethanesulphonic acid $(6 \mathrm{mM})$-buffered standard solution adjusted to $\mathrm{pH} 6.4$. The average slope of the electrodes was $54.8 \mathrm{mV} / \mathrm{pH}$ unit $(n=31)$. The $\mathrm{pH}$ sensitivity of the electrodes was not influenced by the chemicals used in the present experiments. During the experiments, the double-barrelled $\mathrm{pH}$-sensitive microelectrodes were inserted into the centre of the spinal roots for continuous measurement of the $\mathrm{pH}_{e}$

\section{Data and statistics}

Data were recorded, stored and analysed (averaged) on a digital oscilloscope (Nicolet 4562). Data are expressed as mean \pm S.E. (standard error). Statistical analysis was performed by an unpaired two-tailed $t$-test to assess signiticance of differences. Differences were considered to bc significant at $P<0.05\left(^{*}\right)$, highly significant at $P<0.01\left(^{* *}\right.$ ) and extremely significant at $P<0.001(* * *)$.

\section{Physiological solutions}

The standard solution contained (in $\mathrm{mM}$ ): $118 \mathrm{NaCl}$, $3 \mathrm{KCl}, 1.5 \mathrm{CaCl}_{2}$ and $1 \mathrm{MgCl}_{2}, \mathrm{HCO}_{3}^{-}$-buffered solutions consisted of the standard solution plus $25 \mathrm{mM} \mathrm{NaHCO}$ and $1.2 \mathrm{mM} \mathrm{NaH}_{2} \mathrm{PO}_{4}$, equilibrated with $5 \% \mathrm{CO}_{2} / 12 \%$ $\begin{array}{llllll}\mathrm{O}_{2} / 83 \% & \mathrm{~N}_{2} & \text { (normoxia) or } 5 \% & \mathrm{CO}_{2} / 95 \% & \mathrm{~N}_{2} & \text { (hypoxia). }\end{array}$ $\mathrm{HCO}_{3}$-free solutions consisted of the standard solution plus $20 \mathrm{mM}$ sodium gluconate and $6 \mathrm{mM}$ HEPES and were bubbled with $12 \% \mathrm{O}_{2} / 88 \% \mathrm{~N}_{2}$ (normoxia) or ultra pure argon (hypoxia). The glucose concentration in all solutions was $2.5 \mathrm{mM}$. L-Lactate ( $\mathrm{Na}$ - or Li-salt), D-lactate (Li-salt), pyruvate ( $\mathrm{Na}$-salt) and propionate ( $\mathrm{Na}$-salt) were added to the standard solution in their crystalline form. 2-Hydroxy-2-methylpropionate ( $\alpha$-hydroxyisobutyrate, free acid) was stored as a neutralized stock solution in water. $\alpha$-Cyano-4-hydroxycinnamic acid (CHC), HPL, 4,4'-diisothiocyanostilbene-2,2'-disulphonate (DIDS), 4,4'-dibenzamidostilbene-2,2'-disulphonic acid ( $\mathrm{Na}_{2}$-salt, DBDS) and amiloride were dissolved in dimethyl sulphoxide $(0.3 \%)$. The buffering power in solutions containing $\mathrm{CHC}$ was adjusted to the value of the standard solution by reducing the HEPES concentration. The osmolarity of all solutions was kept constant by reducing the concentration of $\mathrm{NaCl}$ in the standard solution. The final $\mathrm{pH}$ was adjusted to 7.4 by addition of $\mathrm{NaOH}$. All chemicals in this study were purchased from Sigma, Munich, Germany, except for DBDS. which was synthesized as described previously. ${ }^{33}$ Ultra pure argon was obtained from Linde AG, Unterscheißheim. Germany.

\section{RESULTS}

\section{Lactate-induced changes in extracellular $\mathrm{pH}$}

A stable $\mathrm{pH}_{\mathrm{e}}$ between 7.2 and 7.3 in the centre of isolated rat spinal roots was observed a few minutes after the insertion of the double-barrelled $\mathrm{pH}$ sensitive microelectrodes. Changes in the L-lactate concentration of the bathing solution (at constant bath $\mathrm{pH}$ ) led to transient shifts in $\mathrm{pH}_{\mathrm{e}}$. The extent of changes in $\mathrm{pH}_{e}$ was dependent on the buffering power of the bathing solution. Averaged $\mathrm{pH}_{\mathrm{e}}$ recordings of this effect from three different spinal roots are illustrated in Fig. 1. First, $30 \mathrm{mM}$ L-lactate was added to $\mathrm{CO}_{2} / \mathrm{HCO}_{3}^{-}$-buffered bathing solutions in exchange for an equimolar concentration of chloride (Fig. 1A). This change in the ionic composition did not alter the $\mathrm{pH}$ of the bathing solution. However, a transient alkaline shift in $\mathrm{pH}_{\mathrm{e}}$ of about $0.04 \mathrm{pH}$ units was observed in the spinal roots. Conversely, a transient acid shift of about $0.06 \mathrm{pH}$ units occurred after withdrawal of L-lactate from the bathing solution. Afterwards, an identical experimental protocol was performed with an unchanged position of the $\mathrm{pH}$-sensitive microelectrode in the same spinal roots. This time L-lactate $(30 \mathrm{mM})$ was applied during superfusion of the spinal roots with HEPES-buffered solution (Fig. 1B), L-Lactateinduced changes in $\mathrm{pH}_{\mathrm{e}}$ were much enhanced under these conditions: $0.14 \mathrm{pH}$ units during the alkaline transient and $0.20 \mathrm{pH}$ units during the acid transient, respectively. In contrast, the resting $\mathrm{pH}_{\mathrm{e}}$ of the spinal 
A

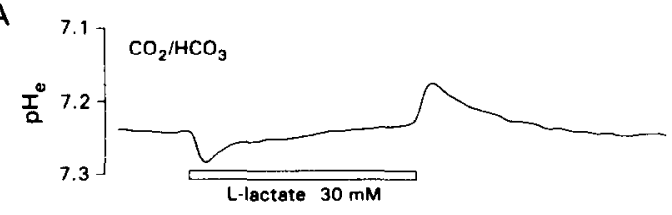

B

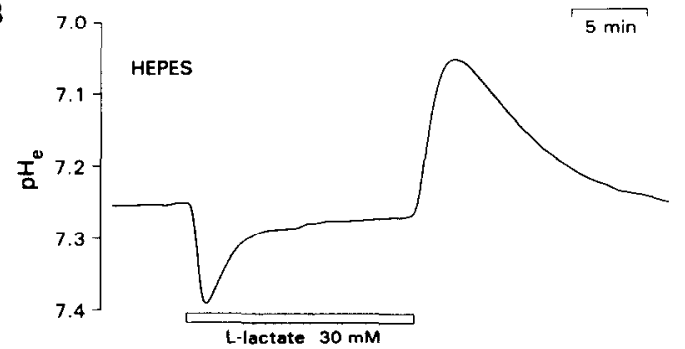

Fig. 1. Effects of L-lactate on $\mathbf{p H}_{e}$ in the centre of isolated rat spinal roots in solutions with different buffering power. (A) Sodium chloride $(30 \mathrm{mM})$ in the bathing solution (buffered with $5 \% \mathrm{CO}_{2} / 25 \mathrm{mM} \mathrm{HCO}_{3}^{-}$) was replaced by an equimolar concentration of sodium L-lactate during the period indicated by the bar (at constant bath $\mathrm{pH}$ ). (B) The same experimental protocol was performed at constant position of the $\mathrm{pH}$-sensitive microelectrodes after the buffer in the saline was changed from $\mathrm{CO}_{2} / \mathrm{HCO}_{3}^{-}$to HEPES $(6 \mathrm{mM})$. The figure shows the averaged data from three experiments.

roots was not altered by the transition from $\mathrm{CO}_{2} / \mathrm{HCO}_{3}^{-}$-buffered to HEPES-buffered solutions. As a consequence of this observation, all of the following experiments were performed in HEPESbuffered $\mathrm{HCO}_{3}^{-}$-free bathing solutions in order to reduce the buffering power of the bathing solution and thereby to augment changes in $\mathrm{pH}_{e}$.

To study the concentration dependence of the effects of L-lactate on $\mathrm{pH}_{\mathrm{e}}$, different spinal roots

A
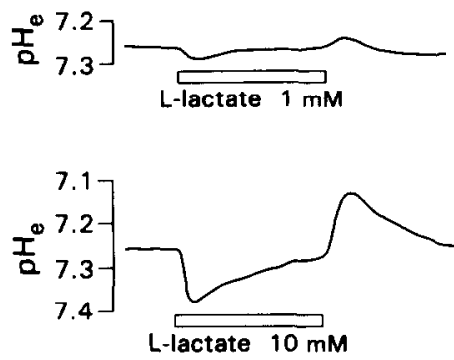

B

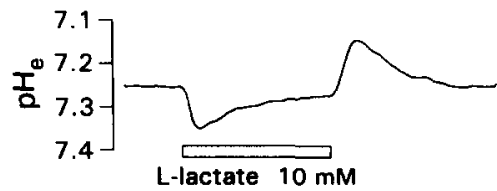

were exposed to various L-lactate concentrations. Figure 2A illustrates changes in $\mathrm{pH}_{e}$ induced by addition and withdrawal of $1,3,10$ and $30 \mathrm{mM}$ L-lactate. A clear increase in the magnitude and the initial rise of both alkaline and acid transients was observed with higher concentrations of L-lactate. Quantitatively, the mean changes in $\mathrm{pH}_{\mathrm{e}}$ seen during the application of $1,3,10$ and $30 \mathrm{mM}$ L-lactate were $0.02,0.07,0.11$ and $0.17 \mathrm{pH}$ units (alkaline shifts) and $0.03,0.08,0.13$ and $0.20 \mathrm{pH}$ units (acid shifts), respectively (see also Fig. 3B).

One feature that may characterize the transport mechanism for lactate is its stereoselectivity. For example, the lactate-proton co-transporters present in erythrocytes ${ }^{11}$ and hepatocytes ${ }^{13}$ have a much higher affinity for L-lactate than for D-lactate. In contrast, the transporters in cardiac muscle ${ }^{30}$ and Ehrlich ascites tumour cells ${ }^{41}$ are much less stereoselective for the L-isomer. Therefore, we studied the effects of both L-lactate and D-lactate on $\mathrm{pH}_{\mathrm{e}}$ of the same spinal roots. The results are shown in Fig. 2B (mean of three $\mathrm{pH}_{\mathrm{e}}$ recordings). Each spinal root was exposed consecutively to $10 \mathrm{mM}$ L-lactate and D-lactate. However, qualitatively and quantitatively similar changes in $\mathrm{pH}_{e}$ were observed between L-lactate and D-lactate (no significant difference).

\section{Effects of different organic anions on extracellular $\mathrm{pH}$}

According to the method of addition and withdrawal of weak acids (for review see Ref. 35), several organic anions have been described to produce intracellular and extracellular $\mathrm{pH}$ changes due to transmembrane diffusion of the undissociated weak acid and/or co-transported with protons. ${ }^{9,27}$ In order to compare the effects of L-lactate on $\mathrm{pH}_{e}$ with
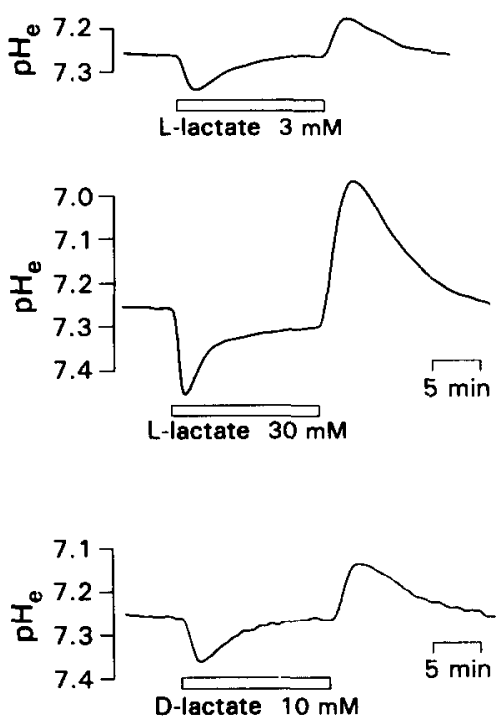

Fig. 2. (A) Changes in $\mathrm{pH}_{\mathrm{e}}$ of isolated spinal roots induced by various L-lactate concentrations. Different spinal roots were exposed to $1,3,10$ and $30 \mathrm{mM}$ L-lactate and $\mathrm{pH}_{e}$ recordings were averaged for any individual concentration $(n=4-11)$. (B) Comparison of the effects of $\mathrm{L}$ - and D-lactate on $\mathrm{pH}_{\mathrm{c}}$ of spinal roots. Each spinal root was exposed consecutively, first to $10 \mathrm{mM}$ L-lactate and then to an equimolar concentration of D-lactate (mean of three experiments). 
A
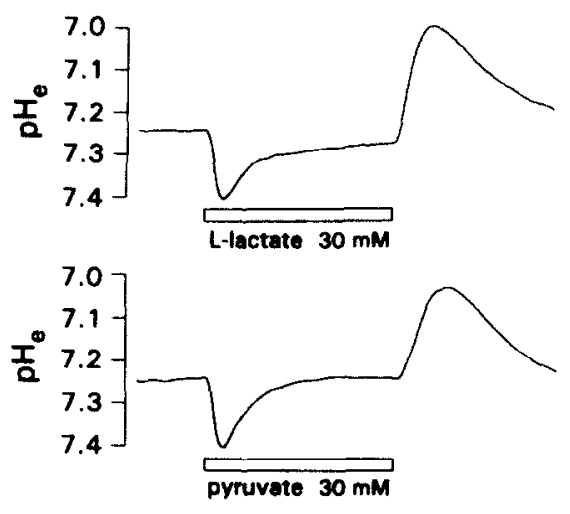

B

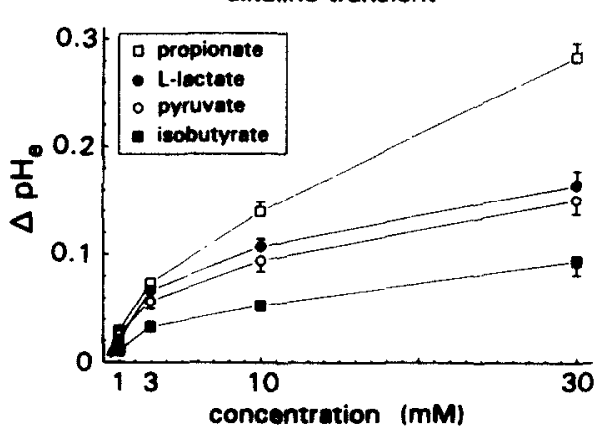

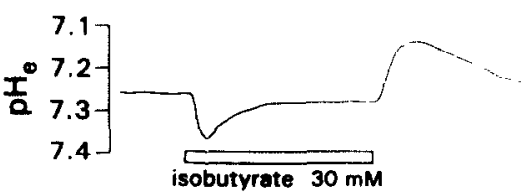
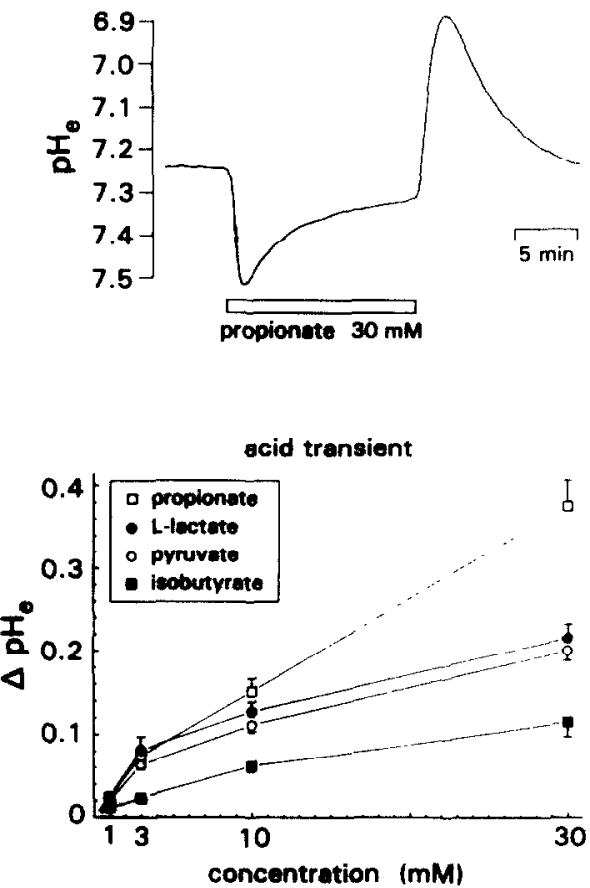

Fig. 3. Effects of different organic anions on $\mathrm{pH}_{\mathrm{e}}$ of isolated spinal roots. (A) Average $\mathrm{pH}_{\mathrm{e}}$ recordings from different spinal roots exposed to $30 \mathrm{mM}$ L-lactate, pyruvate, 2-hydroxy-2-methylpropionate (isobutyrate) and propionate $(n=4-6)$. (B) Comparison of the maximum levels of recorded $\mathrm{pH}_{\mathrm{e}}$ changes induced by propionate, L-lactate, pyruvate and isobutyrate. Calculated values of the mean maximum alkaline (left part) and acid transients (right part) are plotted as a function of tested anion concentrations of $1,3,10$ and $30 \mathrm{mM}$ (points show mean $\pm \mathrm{S}$.E., $n=4-12$ ).

the behaviour of other organic anions in spinal roots, we studied the effects on $\mathrm{pH}_{\mathrm{e}}$ of pyruvate, 2-hydroxy2-methylpropionate ( $\alpha$-hydroxyisobutyrate) and propionate in concentrations of $1,3,10$ and $30 \mathrm{mM}$. Averaged $\mathrm{pH}_{\mathrm{e}}$ recordings obtained from different spinal roots exposed to $30 \mathrm{mM}$ L-lactate, pyruvate, $\alpha$-hydroxyisobutyrate and propionate are shown in Fig. 3A. For comparison, the mean values of alkaline and acid transients for each individual organic anion were taken from $\mathrm{pH}_{\mathrm{e}}$ recordings and plotted as a function of anion concentration. This is shown in Fig. 3B. At $30 \mathrm{mM}$ there was a clear difference between the tested anions: largest effects on $\mathrm{pH}_{\mathrm{e}}$ were observed with propionate $>$ L-lactate $\approx$ pyruvate $>$ $\alpha$-hydroxyisobutyrate. In contrast, at $3 \mathrm{mM}$ the $\mathrm{pH}_{\mathrm{e}}$ transients caused by propionate, L-lactate and pyruvate were nearly similar in size, but still discernible from those obtained with $\alpha$-hydroxyisobutyrate.

Effects of inhibitors of lactate-proton co-transporter on anion-induced extracellular $\mathrm{pH}$ transients

In order to investigate further the role of a specific transporter in the $\mathrm{pH}_{\mathrm{e}}$ responses of spinal roots to addition and withdrawal of lactate, we studied the effects of well-characterized inhibitors of such transporters. For these experiments we used both $\mathrm{CHC}^{16,18}$ and DBDS. ${ }^{33}$ These compounds were tested on $\mathrm{pH}_{\mathrm{e}}$ shifts induced by L-lactate and propionate in order to discriminate between facilitated transport and passive diffusion; the latter should be the dominant mechanism for transmembrane propionate movements ${ }^{9}$ and insensitive to inhibitors. Therefore, spinal roots were exposed consecutively to $10 \mathrm{mM} \mathrm{L-lactate}$ and propionate, first in the absence and then in the presence of the inhibitors. Figure 4A shows the effects of $\mathrm{CHC}$. observed in four different spinal roots. $\mathrm{pH}_{\mathrm{e}}$ transients induced by L-lactate were reduced significantly in the presence of $5 \mathrm{mM} \mathrm{CHC} \mathrm{(left} \mathrm{part),} \mathrm{whereas} \mathrm{those}$ induced by propionate remained unaltered (right part). In addition, $5 \mathrm{mM}$ C.HC significantly reduced changes in $\mathrm{pH}_{\mathrm{e}}$ obtained with $10 \mathrm{mM}$-lactate and pyruvate (data not shown). Similar observations in another four spinal roots were made with DBDS (Fig. 4B). DBDS $(150 \mu \mathrm{m})$ caused significant inhibition of L-lactate-induced $\mathbf{p H}_{\mathrm{e}}$ shifts (left part), but was without significant effect on changes in $\mathrm{pH}_{c}$ produced by propionate (right part). 
A

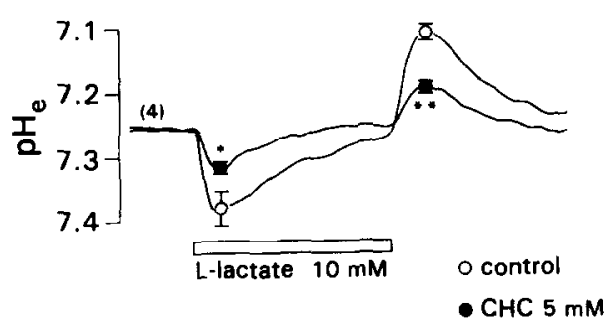

B

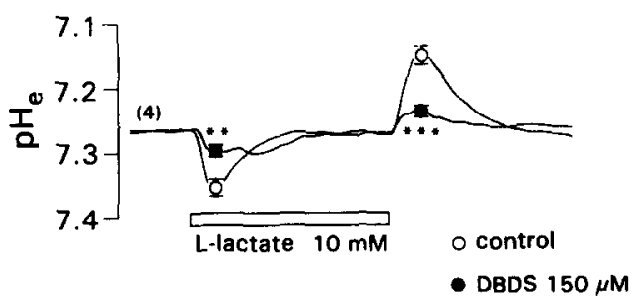

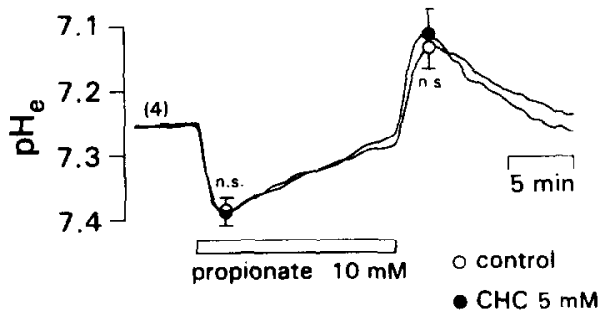

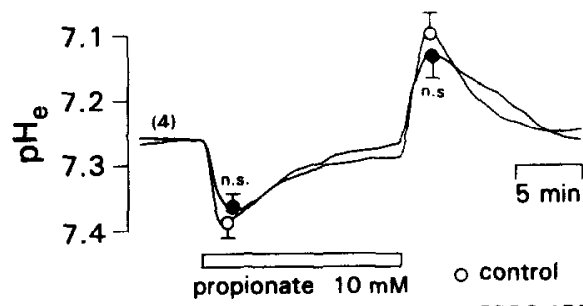

- DBDS $150 \mu \mathrm{M}$

Fig. 4. Effects of CHC ( $5 \mathrm{mM}$; A) and DBDS $\left(150 \mu \mathrm{M}\right.$; B) on $\mathrm{pH}_{c}$ shifts of spinal roots induced by L-lactate and propionate. Each spinal root was exposed consecutively to $10 \mathrm{mM}$ L-lactate and propionate in the normal standard solution and afterwards in the presence of the inhibitor. Averaged $\mathrm{pH}_{\mathrm{e}}$ recordings obtained with L-lactate (left part) and propionate (right part) are superimposed for both conditions, control vs presence of the inhibitor (point show mean \pm S.E.; ${ }^{*} P<0.05,{ }^{* *} P<0.01,{ }^{* * *} P<0.001$; n.s., not significant; numbers are given in parentheses).

\section{Hypoxia-induced extracellular acidosis}

Superfusion of the spinal roots with hypoxic solutions resulted in an extracellular acidification that was maintained over the entire duration of hypoxia. A typical recording from a spinal root which was
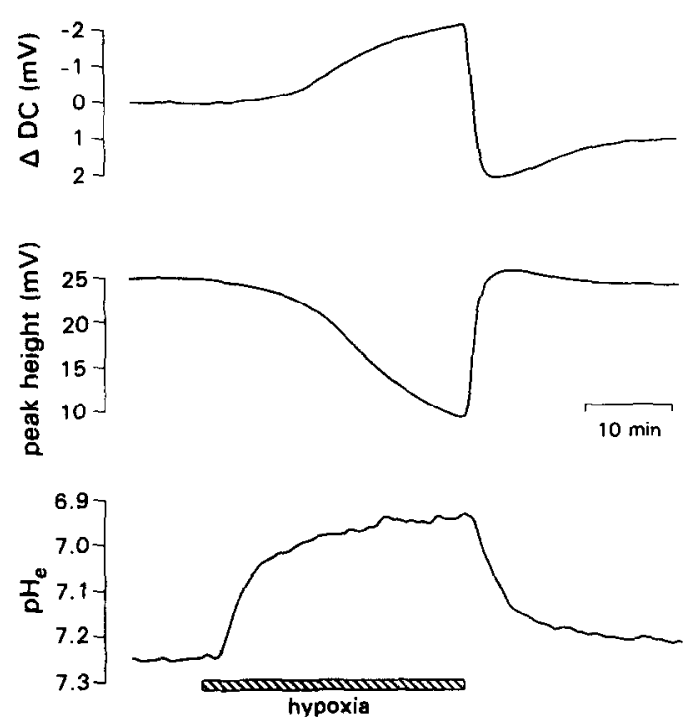

Fig. 5. Original recording from an isolated spinal root before, during and after superfusion with hypoxic solution (hypoxia indicated by the striped bar). Parameters shown are extracellular recorded d.c. potential ( $\triangle D C$, upper part), compound nerve action potential amplitude (peak height, middle part) and $\mathrm{pH}_{\mathrm{c}}$ (lower part). Note that the extracellular acidification is maintained during the entire period of hypoxia. exposed to hypoxia for $30 \mathrm{~min}$ is shown in Fig. 5. The hypoxia-induced changes in extracellular recorded d.c. potential (upper part) and amplitude of compound nerve action potential (peak height, middle part) were accompanied by an extracellular acidification of about $0.3 \mathrm{pH}$ units (lower part). Changes in the first two parameters were always monitored simultaneously to the $\mathrm{pH}_{e}$ recording in order to estimate the sensitivity of the spinal roots to hypoxia. ${ }^{38}$ The mean value of the extracellular acidification in different spinal roots was $0.27 \pm 0.03 \mathrm{pH}$ units $(n=16)$ after exposure to hypoxia for $30 \mathrm{~min}$.

Effects of lactate transport inhibitors on hypoxiainduced extracellular acidosis

Extracellular acid shifts may result from proton extrusion as a consequence of cellular $\mathrm{pH}$ regulation. ${ }^{7}$ If so, they should be sensitive to specific inhibitors of proton extrusion mechanisms. In order to investigate the possible contribution of a lactate-proton cotransporter to extracellular acid shifts during hypoxia, we studied the effects of $\mathrm{CHC}$ on the hypoxia-induced acidification. The results are shown in Fig. 6. CHC, added at a concentration of $10 \mathrm{mM}$ to the normal, oxygenated bathing solution, did not change $\mathrm{pH}_{\mathrm{c}}$ of the spinal roots (Fig. 6A). However, a clear effect of this compound on $\mathrm{pH}_{\mathrm{e}}$ was seen during hypoxic superfusion of the spinal roots. $\mathrm{CHC}$ added to the hypoxic solution $15 \mathrm{~min}$ after the onset of hypoxia immediately suppressed the extracellular acidification (Fig. 6C), which was normally maintained during the entire length of hypoxic superfusion (see Fig. 6B). As a consequence, $\mathrm{pH}_{c}$ of the spinal 


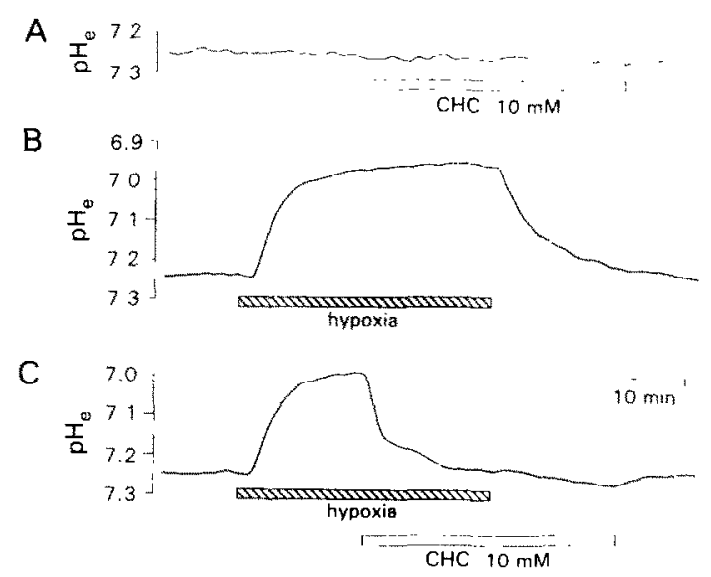

Fig. 6. Effects of $\mathrm{CHC}$ on $\mathrm{pH}_{e}$ of isolated spinal roots during normoxic and hypoxic superfusion. (A) Lack of effect of $10 \mathrm{mM} \mathrm{CHC}$ added to the normal, oxygenated bathing solution. (B) Typical course of exiracellular acidification maintained during the entire period of hypoxia in the absence of an inhibitor. (C) Alkaline-going shift in $\mathrm{pH}_{\mathrm{e}}$ induced by $10 \mathrm{mM} \mathrm{CHC}$, added to the hypoxic bathing solution $15 \mathrm{~min}$ after the onset of hypoxia (each curve represents averaged data from three spinal roots; experiments shown in $\mathrm{A}$ and $\mathrm{C}$ were performed on the same spinal roots).

roots returned towards the resting level after the application of $\mathrm{CHC}$.

A clear reduction of the hypoxia-induced extracellular acidification was also observed when spinal roots were preincubated with either $\mathrm{CHC}$ or DBDS before they were exposed to hypoxia. This is shown in Fig. 7. At the beginning of each experiment, a short period of hypoxic superfusion was performed in order to estimate the size of hypoxia-induced extracellular acid shifts before the inhibitor was added (control). After $\mathrm{pH}_{\mathrm{e}}$ recovery, spinal roots were incubated with $6 \mathrm{mM} \mathrm{CHC} \mathrm{(Fig.} 7 \mathrm{~A}$ ) of $150 \mu \mathrm{M}$ DBDS (Fig. 7B) for $30 \mathrm{~min}$ and exposed to hypoxia in the presence of the inhibitors. Both $\mathrm{CHC}$ and DBDS caused significant reduction of the hypoxiainduced extracellular acid shifts: quantitatively. $80 \%$ inhibition was observed with $\mathrm{CHC}$ (from $0.25+0.03$ during control to $0.05 \pm 0.02 \mathrm{pH}$ units, $n=6$ ), whilst $56 \%$ inhibition occurred with DBDS (from $0.25 \pm 0.03$ during control to $0.11 \pm 0.03 \mathrm{pH}$ units. $n=3$ ). This observation was not a consequence of repetitive hypoxic superfusion. since in the absence of inhibitors the interstitial acidifications produced by two subsequent control periods of hypoxia were similar in size (three observations, data not shown).

In contrast to CHC and DBDS, $10 \mathrm{mM} \mathrm{HPL}$, it weak blocker of lactate transport in Ehrlich ascites tumour cells." was without effect on extracellular acid shifts during hypoxia in spinal roots $(n=3$. data not shown).

Hypoxia-induced extracellular acidification in the presence of amiloride and 4,4'-di-isothiocyanostilbene2,2'-disulphonate

Hypoxia-induced extracellular acid shifts were not completely blocked by inhibitors of lactate transport. Part of the remaining acidification could be due to proton extrusion by other mechanisms involved in cellular $\mathrm{pH}$ regulation. Therefore, we studied the effects of amiloride, a blocker of the $\mathrm{Na}^{+} / \mathrm{H}^{+}$antiport, ${ }^{22}$ and of DIDS, an inhibitor of inorganic anion exchange. ${ }^{6}$ Averaged $\mathrm{pH}_{\mathrm{e}}$ recordings from spinal roots that were preincubated with amiloride and DIDS are shown in Fig. 8 . Neither amiloride $(1 \mathrm{mM}$, $n=3$, Fig. 8A) nor DIDS ( $1 \mathrm{mM} . n=4$, Fig. $8 \mathrm{~B}$ ) caused significant inhibition of the extracellular acidification during hypoxia.
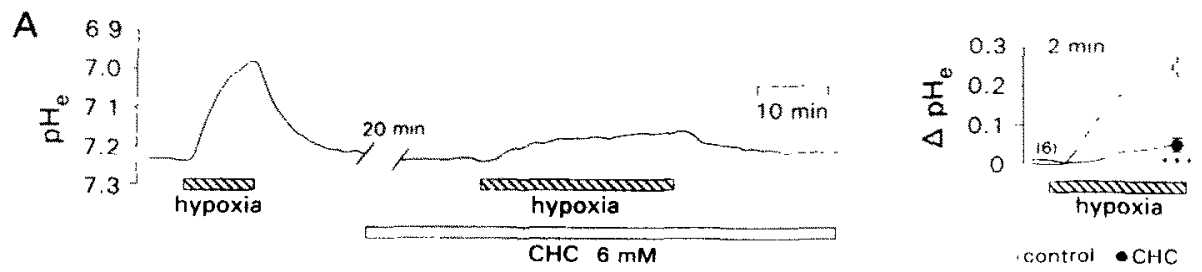

B
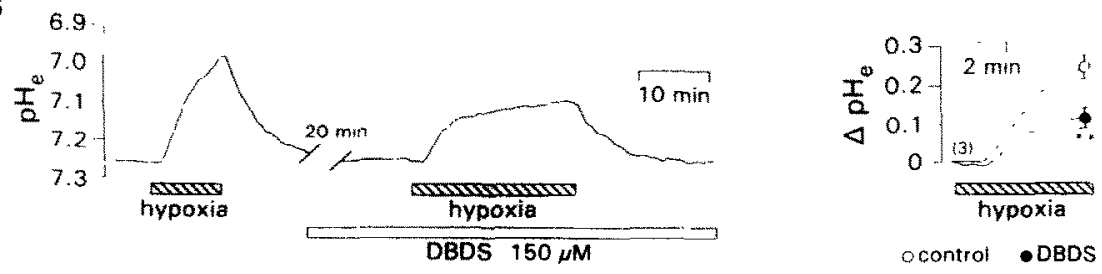

Fig. 7. Hypoxia-induced extracellular acidification before and after preincubation of spinal roots with $\mathrm{CHC}(6 \mathrm{mM}$; A) and DBDS (150 $\mu \mathrm{M}$; B). At the beginning of each experiment, a short period of hypoxia was performed to estimate the extent of acidification under control conditions. After $\mathrm{pH}_{\mathrm{e}}$ recovery, spinal roots were incubated with the inhibitor for $30 \mathrm{~min}$ and exposed to hypoxia in the presence of the inhibitor. The acidification during the first $10 \mathrm{~min}$ of hypoxia of both conditions (control vs presence of the inhibitor) are superimposed in the right part of the figure (points show mean $\pm S . E .,{ }^{* *} P<0.01,{ }^{* * *} P<0.001$ : numbers are given in parentheses). 

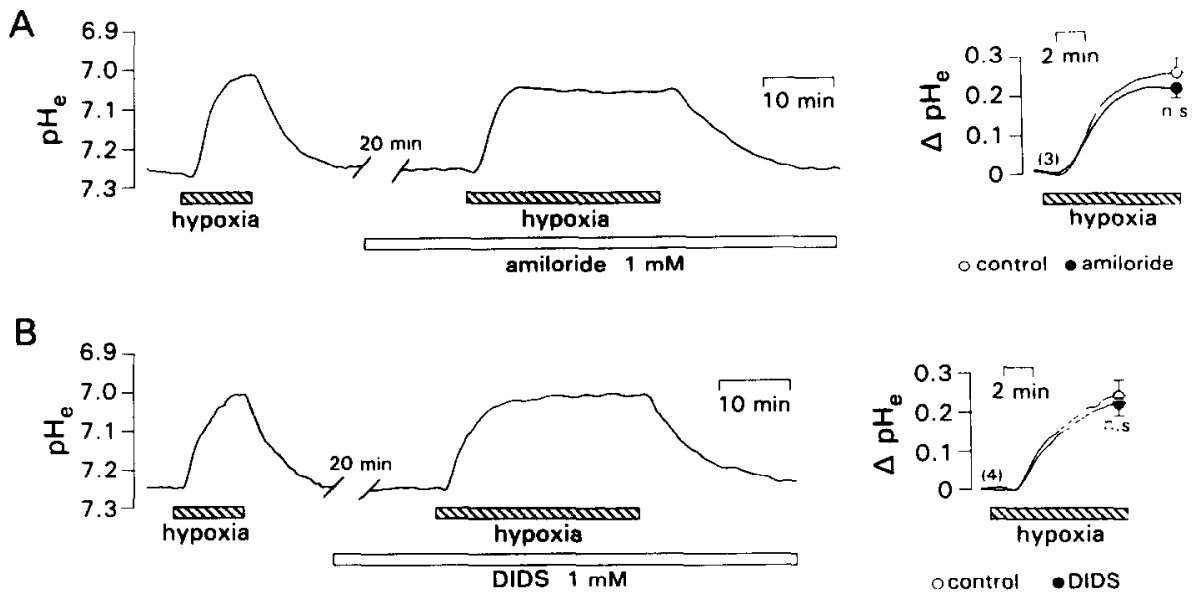

Fig. 8. Hypoxia-induced extracellular acidification before and after preincubation of spinal roots with amiloride (1 mM; A) and DIDS ( $1 \mathrm{mM}$; B). The experimental protocol shown here is identical to Fig. 7. The acidification during the first $10 \mathrm{~min}$ of hypoxia is superimposed for both conditions: control vs presence of the inhibitor (right part; points show mean \pm S.E.; n.s., not significant; numbers are given in parentheses).

\section{DISCUSSION}

\section{Lactate-proton co-transport}

Addition and withdrawal of lactate (and other organic anions) led to transient shifts in $\mathrm{pH}_{\mathrm{e}}$ in isolated rat spinal roots. The transient nature of these $\mathrm{pH}_{\mathrm{e}}$ shifts is probably due to the rapid net cellular uptake and release, respectively, of lactate and protons. A steady state between uptake and release, i.e. no net transport, seems to be reached after a few minutes. As a consequence of this situation $\mathrm{pH}_{e}$ returns to its baseline level.

Three different mechanisms for cellular uptake and release of lactate have been described. ${ }^{10,17}$ These three components of transmembrane lactate transfer are (a) an anion exchange system, (b) non-ionic diffusion and (c) facilitated lactate-proton cotransport (for review see Ref. 32). Our data show that an important part of cellular lactate transport in rat spinal roots occurs via the lactate-proton co-transporter. There are several lines of evidence for this conclusion. Transient shifts in $\mathrm{pH}_{\mathrm{e}}$ accompanying passive changes in extracellular lactate concentration at a constant bath $\mathrm{pH}$ of 7.4 indicate co-transport of lactate and protons. The concentration of lactic acid $\left(\mathrm{p} K_{a} 3.86\right)$ existing in the undissociated form is less than $0.1 \%$ of the total lactate concentration when the interstitial $\mathrm{pH}$ is about 7.2. Consequently, diffusion is unlikely to account for the observed changes in $\mathrm{pH}_{e}$, which suggests that a proton-linked lactate transporter may be operating.

This conclusion is strengthened when effects of L-lactate on $\mathrm{pH}_{\mathrm{e}}$ are compared with $\mathrm{pH}_{\mathrm{e}}$ changes induced by pyruvate, 2-hydroxy-2-methylpropionate ( $\alpha$-hydroxyisobutyrate) and propionate. The rate of passive transmembrane movements of organic anions should be determined by their $\mathrm{p} K_{a}$ values and lipid solubility., ${ }^{9,27}$ With regard to diffusion rates for different organic anions estimated by Marrannes et al. ${ }^{27}$ larger extracellular $\mathrm{pH}$ transients would be expected for propionate $>\alpha$-hydroxyisobutyrate $>$ L-lactate $>$ pyruvate. In spinal roots, however, changes in $\mathrm{pH}_{\mathrm{e}}$ induced by $\mathrm{L}$-lactate and pyruvate were similar in size and significantly larger than those induced by $\alpha$-hydroxyisobutyrate. The $\mathrm{p} K_{a}$ value for $\alpha$-hydroxyisobutyrate is 4.0 and it would be expected to be significantly more lipidsoluble than L-lactate and pyruvate; hence diffusion would be expected to be faster than with L-lactate and pyruvate. Thus our data imply that $\alpha$-hydroxyisobutyrate is a poor substrate for the carrier responsible for lactate and pyruvate transport. This finding is in accordance with that of Poole et al., ${ }^{31}$ who showed that the affinity of the monocarboxylate carrier in erythrocytes and cardiac myocytes to L-lactate and pyruvate was nearly 100 -fold higher than for $\alpha$-hydroxyisobutyrate. Discrepancies between the observed and expected $\mathrm{pH}_{e}$ changes are also obvious at $3 \mathrm{mM}$, where the effects of L-lactate and pyruvate are similar to the effects of propionate, and therefore provide further evidence for an additional facilitated transport of L-lactate and pyruvate.

Stereospecificity is also a well-documented property of lactate transport in erythrocytes ${ }^{11}$ and hepatocytes, ${ }^{13}$ whereas there is no stereoselectivity in Ehrlich ascites tumour cells. ${ }^{41}$ In addition, the transporter in tumour cells is the only known lactate transporter for which lactate is not a less effective substrate than pyruvate. Lactate transport in the rat spinal roots shows similarities to the data obtained with tumour cells, since (a) changes in $\mathrm{pH}_{e}$ during the application of either L- or D-lactate were of similar size and (b) L-lactate was as good a substrate as pyruvate. 
Effects of inhibitors of lactate transport on anioninduced extracellular $\mathrm{pH}$ transients

Transient shifts in ${ }^{\circ} \mathrm{pH}_{\mathrm{e}}$ induced by L-lactate, D-lactate and pyruvate were reduced by $\mathrm{CHC}$, a blocker of all known lactate-proton cotransporters. ${ }^{13,15,16,18,30,41}$ The CHC sensitivity of shifts in $\mathrm{pH}_{e}$ caused by these compounds clearly distinguished the underlying mechanisms from those responsible for propionate-induced $\mathrm{pH}_{\mathrm{e}}$ shifts, which were $\mathrm{CHC}$-insensitive. Although propionate is a substrate for lactate transporters, ${ }^{17,41}$ it is capable of rapid diffusion across the plasma membrane." This may explain the lack of effect of $\mathrm{CHC}$ on propionateinduced $\mathrm{pH}_{\mathrm{e}}$ shifts in spinal roots. In contrast, sensitivily to $\mathrm{CHC}$ of lactate- and pyruvate-induced $\mathrm{pH}_{\mathrm{e}}$ changes indicates a low rate of transmembrane diffusion for lactic and pyruvic acid and that facilitated transport for lactate (or pyruvate) and protons is the dominant route under these conditions. Similar results with $\mathrm{CHC}$ have also been described in frog muscle, ${ }^{28}$ sheep Purkinje fibres, ${ }^{9}$ erythrocytes ${ }^{3.7}$ and Ehrlich ascites tumour cells, ${ }^{41}$ where lactateinduced changes in intracellular or extracellular $\mathrm{pH}$ were CHC-sensitive, contrary to the effects induced by propionate.

Although $\mathrm{CHC}$ is an effective inhibitor of lactate-proton co-transport, it suffers from two disadvantages. Firstly, the phenolic hydroxyl group has a $\mathrm{p} K$ value of about 8 , which causes the buffering power of solutions containing it to be enhanced significantly. Secondly, it may enter cells where it is an extremely potent inhibitor of mitochondrial pyruvate transport (see below). ${ }^{15}$ Therefore, we used DBDS, a membrane impermeant lactate transport inhibitor with a substantially lower $K_{i}$ than $\mathrm{CHC}$ under physiological conditions. ${ }^{33}$ A selective inhibition of lactate-induced $\mathrm{pH}_{\mathrm{e}}$ shifts by DBDS without affecting $\mathrm{pH}_{\mathrm{e}}$ transients induced by propionate indicates lactate transport in spinal roots and supports the results obtained with $\mathrm{CHC}$.

\section{Effects of lactate transport inhibitors on hypoxia- induced extracellular acidification}

Exposure of nervous tissue to anoxia results in interstitial acidification. ${ }^{20.42}$ There is strong evidence for lactic acid production as the underlying mechanism since a clear correlation between glucose availability of neural tissue and the extent of hypoxiainduced acidification was found in vivo $o^{8,40}$ and in vitro. ${ }^{25,42}$ However, the manner by which acid appears in the extracellular space is not clear. ${ }^{7}$ Our data indicate that a major part of hypoxia-induced extracellular acidification in isolated rat spinal roots results from a lactate-proton co-transporter. The main evidence for this conclusion comes from the effects of the studied inhibitors of lactate-proton co-transport. CHC, applied before or during hypoxia, strongly reduced the hypoxia-related extracellular acidification. This effect was not due to "unspecific" changes in electrophysiological parameters of the axons since neither alterations in compound nerve action potential amplitude and extracellular d.c. potential nor shifts in $\mathrm{pH}_{\mathrm{t}}$ were observed when $\mathrm{CHC}$ was applied during normoxic conditions. However, changes in lactate formation and release due to reduced mitochondrial pyruvate transport and oxidation after the application of $\mathrm{CHC}^{19}$ cannot be excluded completely. These sideeffects of $\mathrm{CHC}$ on cellular metabolism and buffering power (see above) should not occur with DBDS, since this compound is membrane impermeant ${ }^{3.3}$ and does not buffer in the physiological range. Hence, the results obtained with $\mathrm{CHC}$ are complemented by the observation that DBDS reduced hypoxia-induced extracellular acidification significantly.

HPL, another blocker of lactate transport., ${ }^{41,44}$ failcd to antagonize hypoxia-induced cxtraccllular acidification in spinal roots. This observation is in accordance with the lack of effect of this compound on hypoxia-induced extracellular acidification in hippocampal slices. ${ }^{25}$ However, the most likely reason for this finding seems to be low sensitivity of lactate transport to this compound $(K, 3.6 \mathrm{mM}$ in Ehrlich ascites tumour cells $)^{41}$ rather than the absence of at lactate-proton co-transporter.

Although CHC and DBDS were found to be very potent inhibitors, hypoxia-induced extracellular acidification of spinal roots was not blocked completely in the presence of CHC or DBDS. However, inhibition of lactate transport would not be expected to prevent cellular lactic acid efflux totally. The formation and accumulation of lactic acid will increase when lactate transport in hypoxic tissue is blocked by specific inhibitors, leading to a decrease in intracellular $\mathrm{pH}$. This will happen until a new steady statc of lactic acid production and diffusion is reached. Therefore, part of the remaining acidification during hypoxia in the presence of lactate transport inhibitors may be due to passive diffusion of lactic acid.

Role of $\mathrm{Na}^{+} / \mathrm{H}^{+}$and $\mathrm{Cl}^{-} / \mathrm{HCO}_{3}^{-}$exchange in extracellular acidification during hypoxia

An alternative to passive diffusion of lactic acid and facilitated lactate-proton co-transport would be transmembrane acid extrusion by $\mathrm{Na}^{+} / \mathrm{H}^{+}$and/or $\mathrm{Cl}^{-} / \mathrm{HCO}_{3}^{-}$exchange. In our present study, we did not find evidence for participation of these mechanisms in extracellular acidification.

Firstly, amiloride, a blocker of $\mathrm{Na}^{+} / \mathrm{H}^{+}$antiport, ${ }^{22}$ was without effect on hypoxia-induced extracellular acidification of spinal roots, indicating that this mechanism was not involved in cellular acid extrusion. This finding was unexpected since this transport system is thought to be of importance in the regulation of cytoplasmic $\mathrm{pH},{ }^{14}$ but is in accordance with results from Imai et al. ${ }^{21}$ who showed that $\mathrm{Na}^{+} / \mathrm{H}^{+}$ exchange is not operative under hypoxic conditios in the isolated rat heart. The failure of acid extrusion by 
$\mathrm{Na}^{+} / \mathrm{H}^{+}$exchange during hypoxia in rat spinal roots seems understandable in view of a possible decrease in transmembrane $\mathrm{Na}^{+}$gradient as a consequence of energy deficiency, ${ }^{20}$ and the known inhibition of $\mathrm{Na}^{+} / \mathrm{H}^{+}$antiport by external acidosis. ${ }^{1}$ Furthermore, although a decrease in intra-axonal $\mathrm{pH}$ during hypoxia seems likely, it probably may not pass over the apparent set-point of activation of the $\mathrm{Na}^{+} / \mathrm{H}^{+}$ exchanger. Finally, the contribution to acid extrusion of an amiloride-insensitive $\mathrm{Na}^{+} / \mathrm{H}^{+}$exchanger, as described for cultured hippocampal neurons, ${ }^{34}$ cannot be excluded.

Secondly, an anion-exchange pathway for lactate release, ${ }^{13,30}$ i.e. via $\mathrm{Cl}^{-} / \mathrm{HCO}_{3}^{-}$exchange, seems to be unlikely, since (a) experiments were performed in $\mathrm{HCO}_{3}^{-}$-free solutions and (b) hypoxia-induced extracellular acidification was insensitive to DIDS, an inhibitor of inorganic anion exchange. ${ }^{6}$ This finding is in accordance with observations made by Walz and Mukerji. ${ }^{45}$ These authors excluded an involvement of anion exchange in lactate release of cultured neurons and glial cells because of its insensitivity to DIDS. Whilst the experiments with DIDS rule out a role for the $\mathrm{Cl}^{-} / \mathrm{HCO}_{3}^{-}$antiport, it may be surprising that, in contrast to DBDS, DIDS ( $1 \mathrm{mM}$ ) appeared to have little effect on the lactate transporter in spinal roots.
Reported $K_{i}$ values for DIDS and DBDS as inhibitors of lactate transport into erythrocytes are 40 and $22 \mu \mathrm{M} \cdot{ }^{33}$ This might suggest a difference in sensitivity to inhibitors between the cell types.

\section{CONCLUSION}

Our data indicate the presence of a lactate-proton co-transporter in isolated rat peripheral nerves. However, the observed changes in $\mathrm{pH}_{\mathrm{e}}$ do not allow localization of the transport mechanism to the membrane of axons and/or Schwann cells, since both cell types may contribute to changes in $\mathrm{pH}_{\mathrm{e}}$. Actually, it has been shown that both neurons and glial cells are capable of lactate transport. ${ }^{45,46}$

The functional significance of such a transport system in the mammalian peripheral nervous system still remains speculative. However, the present study shows that the lactate-proton co-transporter is the dominant mechanism responsible for interstitial acidification during nerve hypoxia.

Acknowledgements-We would like to thank Mrs C. Müller for expert technical and secretarial assistance and $\mathrm{Dr} M$. Strupp for participation in some of the preliminary experiments. This work was supported by the Deutsche Forschungsgemeinschaft (SFB 220/B1).

\section{REFERENCES}

1. Aronson P. S., Nee J. and Suhm M. A. (1983) Interaction of external $\mathrm{H}^{+}$with the $\mathrm{Na}^{+} / \mathrm{H}^{+}$exchanger in renal microvillus membrane vesicles. J. biol. Chem. 258, 6767-6771.

2. Assaf H. M., Ricci A. J., Whittingham T. S., Lamanna J. C., Ratcheson R. A. and Lust W. D. (1990) Lactate compartmentation in hippocampal slices: evidence for a transporter. Metab. Brain Disease 5, 143-154.

3. Ballanyi K. and Schlue W. R. (1989) Electrophysiological characterization of a nicotinic acetylcholine receptor on leech neuropile glial cells. Glia 2, 330-345.

4. Beaudry M., Duvallet A., Thieulart L., el Abida K. and Rieu M. (1991) Lactate transport in skeletal muscle cells: uptake in L6 myoblasts. Acta physiol. scand. 141, 379-381.

5. Bonanno J. A. (1990) Lactate-proton co-transport in rabbit corneal epithelium. Curr. Eye Res. 9, 707-712.

6. Cabantchik Z. I. and Rothstein A. (1972) The nature of the membrane sites controlling anion permeability of human red blood cells as determined by studies with disulphonic stilbene derivatives. J. Membrane Biol. 10, 311-330.

7. Chesler M. (1990) The regulation and modulation of pH in the nervous system. Prog. Neurobiol. 34, 401-427.

8. Combs D. J., Dempsey R. J., Maley M., Donaldson D. and Smith C. (1990) Relationship between plasma glucose, brain lactate, and intracellular $\mathrm{pH}$ during cerebral ischemia in gerbils. Stroke 21, 936-942.

9. de Hemptinne A., Marrannes R. and Vanheel B. (1983) Influence of organic acids on intracellular pH. Am. J. Physiol. 245, C178-183.

10. Deuticke B., Beyer E. and Forst B. (1982) Discrimination of three parallel pathways of lactate transport in the human erythrocyte membrane by inhibitors and kinetic properties. Biochim. biophys. Acta 684, 96-110.

11. Deuticke B., Rickert I. and Beyer E. (1978) Stereoselective, SH-dependent transfer of lactate in mammalian erythrocytes. Biochim. biophys. Acta 507, 137-155.

12. Dubinsky W. P. and Racker E. (1978) The mechanism of lactate transport in human erythrocytes. J. Membrane Biol. 44, 25-36.

13. Edlund G. L. and Halestrap A. P. (1988) The kinetics of transport of lactate and pyruvate into rat hepatocytes. Evidence for the presence of a specific carrier similar to that in erythrocytes. Biochem. J. 249, 117-126.

14. Grinstein S. and Rothstein A. (1986) Mechanisms of regulation of the $\mathrm{Na}^{+} / \mathrm{H}^{+}$exchanger. J. Membrane Biol. 90, 1-12.

15. Halestrap A. P. (1975) The mitochondrial pyruvate carrier. Kinetics and specificity for substrates and inhibitors. Biochem. J. 148, 85-96.

16. Halestrap A. P. (1976) Transport of pyruvate and lactate into human erythrocytes. Evidence for the involvement of the chloride carrier and a chloride-independent carrier. Biochem. J. 156, 193-207.

17. Halestrap A. P., Poole R. C. and Cranmer S. L. (1990) Mechanisms and regulation of lactate, pyruvate and ketone body transport across the plasma membrane of mammalian cells and their metabolic consequences. Biochem. Soc. Trans. 18, 1132-1135.

18. Halestrap A. P. and Denton R. M. (1974) Specific inhibition of pyruvate transport in rat liver mitochondria and human erythrocytes by $\alpha$-cyano-4-hydroxycinnamate. Biochem. $J$. 138, 313-316

19. Halestrap A. P. and Denton R. M. (1975) The specificity and metabolic implications of the inhibition of pyruvate transport in isolated mitochondria and intact tissue preparations by $\alpha$-cyano-4-hydroxycinnamate and related compounds. Biochem. J. 148, 97-106. 
20. Hansen A. J. (1985) Effect of anoxia on ion distribution in the brain. Physiol. Rev. 65, 101-148.

21. Imai S., Shi A.-Y., Ishibashi T. and Nakazawa M. (1991) Na+/ $\mathrm{H}^{+}$exchange is not operative under low-flow ischemic conditions. J. molec. cell. Cardiol. 23, 505-517.

22. Johnson J. D., Epel D. and Paul M. (1976) Intracellular $\mathrm{pH}$ and activation of sea urchin eggs after fertilization. Nuture $262,661-664$.

23. Juel C. (1991) Muscle lactate transport studied in sarcolemmal giant vesicles. Biochim. biophys. Acta 1065, 15-20.

24. Kraig R. P., Ferreira-Filho C. R. and Nicholson C. (1983) Alkaline and acid transients in cerebellar micro-environment. J. Neurophysiol. 49, 831-850.

25. Krnjević K. and Walz W. (1990) Acidosis and blockade of orthodromic responses caused by anoxia in rat hippocampal slices at different temperatures. J. Physiol. 422, 127-144.

26. Kuhr W. G., van den Berg C. J. and Korf J. (1988) In vivo identification and quantitative evaluation of carrier-mediated transport of lactate at the cellular level in the striatum of conscious, freely moving rats. J. cerebr. Blood Flow Metab. 8, 848-856.

27. Marrannes R., de Hemptinne A. and Leusen I. (1981) pH aspects of transient changes in conduction velocity in isolated heart fibers after partial replacement of chloride with organic anions. Pfïgers Arch. 389, 199-209

28. Mason M. J. and Thomas R. C. (1988) A microelectrode study of the mechanisms of L-lactate entry into and release from frog sartorius muscle. J. Physiol. 400, 459-479.

29. Mutch W. A. C. and Hansen A. J. (1984) Extracellular $\mathrm{pH}$ changes during spreading depression and cerebral ischemia: mechanisms of brain $\mathrm{pH}$ regulation. J. cerebr. Blood Flow Metab. 4, 17-27.

30. Poole R. C., Halestrap A. P., Price S. J. and Levi A. J. (1989) The kinetics of transport of lactate and pyruvate into isolated cardiac myocytes from guinea-pig. Kinetic evidence for the presence of a carrier distinct from that in erythrocytes and hepatocytes. Biochem. J. 264, 409-418.

31. Poole R. C., Cranmer S. L., Halestrap A. P. and Levi A. J. (1990) Substrate and inhibitor specificity of monocarboxylate transport into heart cells and erythrocytes-further evidence for the existence of 2 distinct carriers. Biochem. J. 269, 827-829.

32. Poole R. C. and Halestrap A. P. (1992) Transport of lactate and other monocarboxylates across mammalian plasma membranes. Am. J. Physiol. (in press).

33. Poole R. C. and Halestrap A. P. (1991) Reversible and irreversible inhibition, by stilbenedisulphonates, of lactate transport into rat erythrocytes. Identification of some new high-affinity inhibitors. Biochem. J. 275, 307-312.

34. Raley-Susman K. L., Cragoe E. J. Jr, Sapolsky R. M. and Kopito R. R. (1991) Regulation of intracellular pH in cultured hippocampal neurons by an amiloride-insensitive $\mathrm{Na}^{+} / \mathrm{H}^{+}$exchanger. J. biol. Chem. 266, 2739-2745.

35. Roos A. and Boron W. F. (1981) Intracellular pH. Physiol. Rev. 61, $296-433$.

36. Roth D. A. and Brooks G. A. (1990) Lactate and pyruvate transport is dominated by a $\mathrm{pH}$ gradient-sensitive carrier in rat skeletal muscle sarcolemmal vesicles. Archs Biochem. Biophys. 279, 386-394.

37. Scheller D., Kolb J. and Tegtmeier F. (1992) Lactate and pH change in close correlation in the extracellular space of the rat brain during cortical spreading depression. Neurosci. Lett. 135, 83-86.

38. Schneider U., Jund R., Nees S. and Grafe P. (1992) Differences in sensitivity to hyperglycemic hypoxia of isolated rat sensory and motor nerve fibers. Ann. Neurol. 31, 605-610.

39. Schneider U., Strupp M., Jund R. and Grafe P. (1992) Lactate-proton co-transport and its activation by hypoxia in the mammalian peripheral nervous system. Pfiügers Arch. 420, R25.

40. Smith M. L., von Hanwehr R. and Siesjö B. K. (1986) Changes in extra- and intracellular pH in the brain during and following ischemia in hyperglycemic and in moderately hypoglycemic rats. J, cereb. Blood Flow Metab. 6, 574-583.

41. Spencer T. L. and Lehninger A. L. (1976) L-Lactate transport in Ehrlich ascites tumour cells. Biochem. J. 154, 405-414.

42. Strupp M. and Jund R., Schneider U. and Grafe P. (1991) Glucose availability and sensitivity to anoxia of isolated rat peroneal nerve. Am. J. Physiol. 261, E389-E394.

43. Trosper T. L. and Philipson K. D. (1987) Lactate transport by cardiac sarcolemmal vesicles. Am. J. Physiol. 252, C483-C489.

44. Walsh P. J. (1987) Lactate transport in toadfish hepatocytes: passive diffusion is sufficient. J. exp. Biol. 130, $295-304$.

45. Walz W. and Mukerji S. (1988) Lactate release from cultured astrocytes and neurons: a comparison. Glia 1, 366-370.

46. Walz W. and Mukerji S. (1990) Simulation of aspects of ischemia in cell culture: changes in lactate compartmentation. Glia 3, 522-528. 